\title{
Deceased donor liver transplantation in an adult recipient with situs inversus totalis: A case report of 10-year clinical sequences following primary and repeat transplantation
}

\author{
Byeong-Gon Na, Shin Hwang, Chul-Soo Ahn, Deok-Bog Moon, Gi-Won Song, \\ Dong-Hwan Jung, Gil-Chun Park, and Sung-Gyu Lee
}

\author{
Division of Hepatobiliary Surgery and Liver Transplantation, Department of Surgery, Asan Medical Center, \\ University of Ulsan College of Medicine, Seoul, Korea
}

\begin{abstract}
The feasibility of liver transplantation (LT) in adult patients with situs inversus (SI) was demonstrated with advances in surgical techniques. However, $\mathrm{SI}$ is very rare, and the experience of LT in adult patients with $\mathrm{SI}$ is very limited. We present a case of an adult patient with SI who underwent deceased-donor LT and late retransplantation because of chronic rejection. A 42-year-old man with SI totalis who suffered from acute-on-chronic hepatic failure because of hepatitis B virus-associated liver cirrhosis and alcoholic liver disease was referred to our center and underwent successful orthotopic deceased-donor whole-liver transplantation. We used a modified piggy-back technique with cavo-cavostomy and inserted a tissue expander for mechanical support of the unstably located liver graft. The patient recovered uneventfully. At 3 years after the first LT, this patient underwent retransplantation because of chronic rejection. In the second LT, we used similar surgical techniques, but performed splenectomy to make space to accommodate the second liver graft. The patient was discharged after long hospitalization. At 5 years after the second LT, he underwent living-donor kidney transplantation because of chronic renal failure developed after the second LT. Currently, he has done well for 10 years after the first LT. In conclusion, SI is a rare anomalous condition hindering LT. Careful perioperative planning with thorough assessment of the donor and recipient livers and use of patient-tailored surgical techniques can lead to successful LT. (Ann Hepatobiliary Pancreat Surg 2020;24:319-325)
\end{abstract}

Key Words: Liver anatomy; Liver transplantation; Whole liver; Malrotation; Cavoplasty

\section{INTRODUCTION}

Situs inversus (SI) is a rare condition characterized by mirror-image orientation of the normal viscera relative to the midline. SI had been once considered to be a contraindication for liver transplantation (LT), ${ }^{1-3}$ but technical advances and accumulation of experience have led to successful LT in patients with SI. LT experience in adult patients with SI is accumulating worldwide, but there are still a small number of case reports in the literature. ${ }^{4-17}$

We herein present a case of an adult patient with SI totalis who successfully underwent deceased-donor whole-liver transplantation and late retransplantation because of chronic rejection.

\section{CASE}

The case was a 42-year-old male patient who had suffered of acute-on-chronic liver failure because of hepatitis B virus-associated liver cirrhosis and alcoholic liver disease. This patient was referred to our center for LT. SI totalis was identified at the pretransplant computed tomography scan (Fig. 1), but detailed studies on vascular anatomy were not done because of severe renal dysfunction. The model for end-stage liver disease (MELD) score was 41 at admission, so he was enrolled in the waiting list with Korean Network for Organ Sharing (KONOS) old status 2A, which provided priority allocation. His height and body weight were $178 \mathrm{~cm}$ and $95 \mathrm{~kg}$, respectively.

Received: June 10, 2020; Revised: June 13, 2020; Accepted: June 13, 2020

Corresponding author: Shin Hwang

Department of Surgery, Asan Medical Center, University of Ulsan College of Medicine, 88 Olympic-ro 43-gil, Songpa-gu, Seoul 05505, Korea Tel: +82-2-3010-3930, Fax: +82-2-3010-6701, E-mail: shwang@amc.seoul.kr

Copyright (C) 2020 by The Korean Association of Hepato-Biliary-Pancreatic Surgery

This is an Open Access article distributed under the terms of the Creative Commons Attribution Non-Commercial License (http://creativecommons.org/ censes/by-nc/4.0) which permits unrestricted non-commercial use, distribution, and reproduction in any medium, provided the original work is properly cited. Annals of Hepato-Biliary-Pancreatic Surgery - pISSN: 2508-5778 - elSSN: 2508-5859 

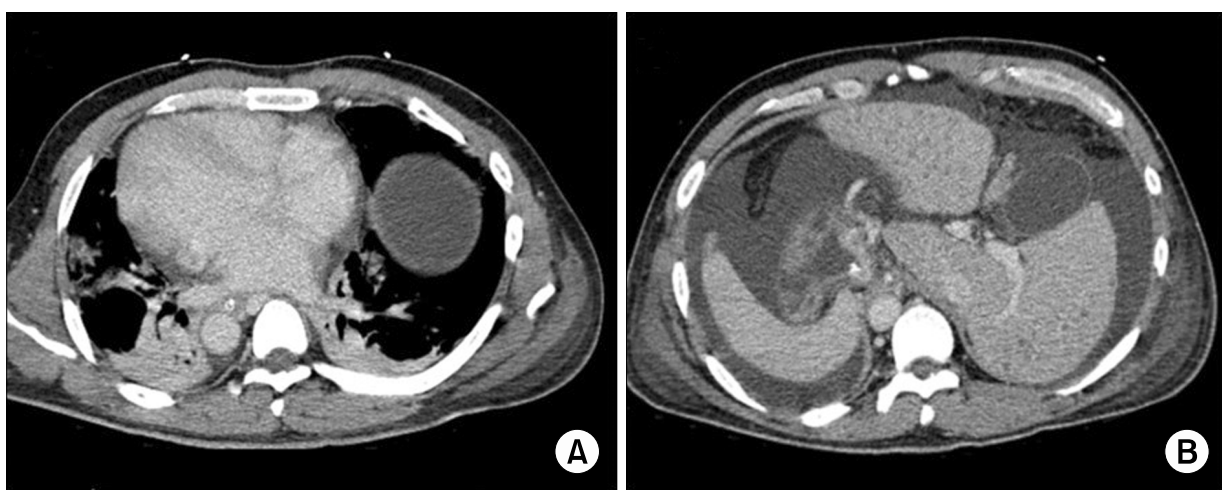

Fig. 1. Pretransplant computed tomography findings showing situs inversus totalis with dextrocardia (A) and mirror-image rotation of the abdominal viscera $(\mathrm{B})$.
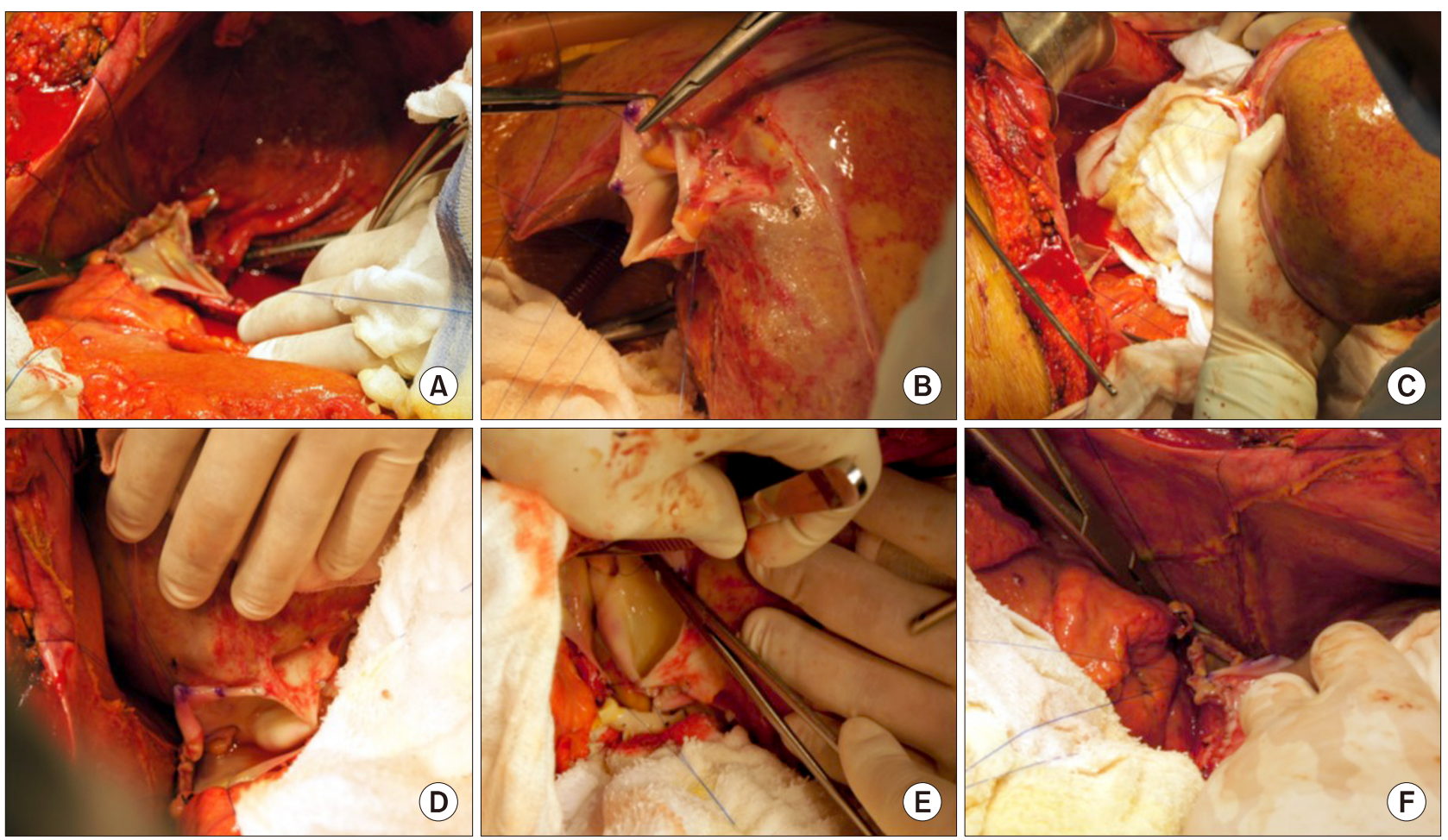

Fig. 2. Intraoperative photographs of graft outflow vein reconstruction using a modified piggyback method. (A) The orifices of the right, middle, and left hepatic vein trunks were opened, and a 5-cm-long longitudinal incision was made at the ventral surface of the retrohepatic inferior vena cava (IVC). (B and C) The corners of the recipient and graft IVC orifices were tagged with 4-0 Prolene sutures, and then a 4-cm-long longitudinal incision was also made at the dorsal surface of the graft IVC. (D and E) These triangular-shaped orifices at the recipient and graft IVCs were matched and then sutured with 4-0 Prolene. (F) The left side of the IVC anastomosis was performed with 4-0 Prolene.

Considering the recipient status of SI, we waited for a deceased donor with a small body size. After eight days of waiting, a whole-liver graft of a 69-year-old female donor was allocated for this patient. Her height and body weight were $159 \mathrm{~cm}$ and $58 \mathrm{~kg}$, respectively. The donor-recipient body weight ratio was 0.61 . The graft weight was $1360 \mathrm{~g}$, so the graft-recipient body weight ratio was 1.43. After laparotomy, the recipient's native liver was removed according to the standard procedures of de- ceased-donor liver transplantation (DDLT). We performed veno-venous bypass using a centrifugal biopump with inflow from the portal vein and left iliac vein. At this stage, the whole-liver graft was temporarily placed within the upper abdominal cavity to assess its proper location and orientation. Since the upper abdominal cavity was large enough to accommodate the whole-liver graft in the orthodox position, we decided to perform a large cavocaval anastomosis using a modified piggyback technique (Fig. 2). 
After clamping of the suprahepatic and retrohepatic inferior vena cava (IVC), the orifices of the right, middle and left hepatic vein trunks were opened altogether to make a large single orifice. In addition, we made a 5-cm-long longitudinal incision at the ventral surface of the retrohepatic IVC to enlarge the anastomotic vein orifice further. The corners of the recipient and graft IVC orifices were tagged with 4-0 Prolene sutures, and then a 4-cm-long longitudinal incision was also made at the dorsal surface of the graft IVC. These triangular-shaped orifices at the recipient and graft IVCs were matched and sutured with 4-0 Prolene. Thereafter, we packed a large bulk of surgical gauzes at the left subphrenic space to sup- port the liver graft. The portal vein was anastomosed under this orientation with gauze packing. We performed hepatic artery reconstruction using branch patches and duct-to-duct biliary anastomosis with insertion of a rubber T-tube (Fig. 3). In order to maintain the orientation of the outflow and inflow vessels of the liver graft in the designed position, we placed a large tissue expander at the left subphrenic space for mechanical support of the liver graft.

The graft function was recovered uneventfully with no surgical complications (Fig. 4), but hospitalization was prolonged because of poor general condition and pneumonia. The water within the tissue expander was gradu-
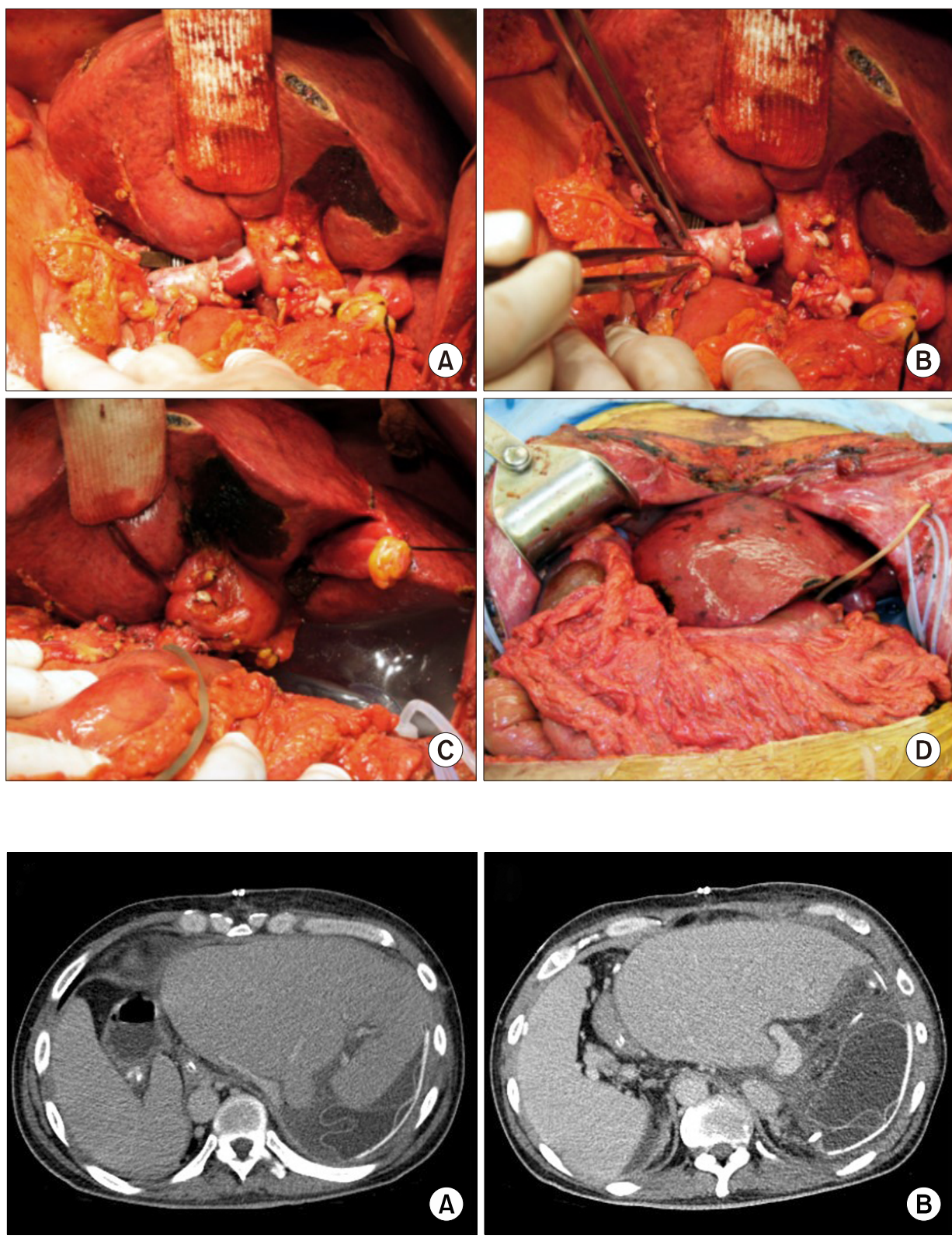

Fig. 4. Posttransplant computed tomography taken 10 days after the first transplantation, showing uneventful reconstruction of the hepatic vein (A) and portal vein (B).
Fig. 3. Intraoperative photographs of graft hilum reconstruction. (A) The portal vein was anastomosed under this orientation with gauze packing. (B) Hepatic artery reconstruction and duct-to-duct anastomosis was done with insertion of a rubber T-tube. (C and D) A large tissue expander was placed at the left subphrenic space for mechanical support of the liver graft. 
ally removed, and the expander was removed at 46 days after transplantation. This patient was finally discharged 63 days after the DDLT.

At 30 months after DDLT, the liver function deteriorated progressively (Fig. 5). Initial liver biopsies sug- gested acute cellular rejection. Subsequent repeated liver biopsies revealed severe cholestasis, mild portal inflammation with bile duct atrophy and loss, and perisinusoidal fibrosis, strongly suggesting chronic rejection. At 34 months after first DDLT, his liver function deterio-
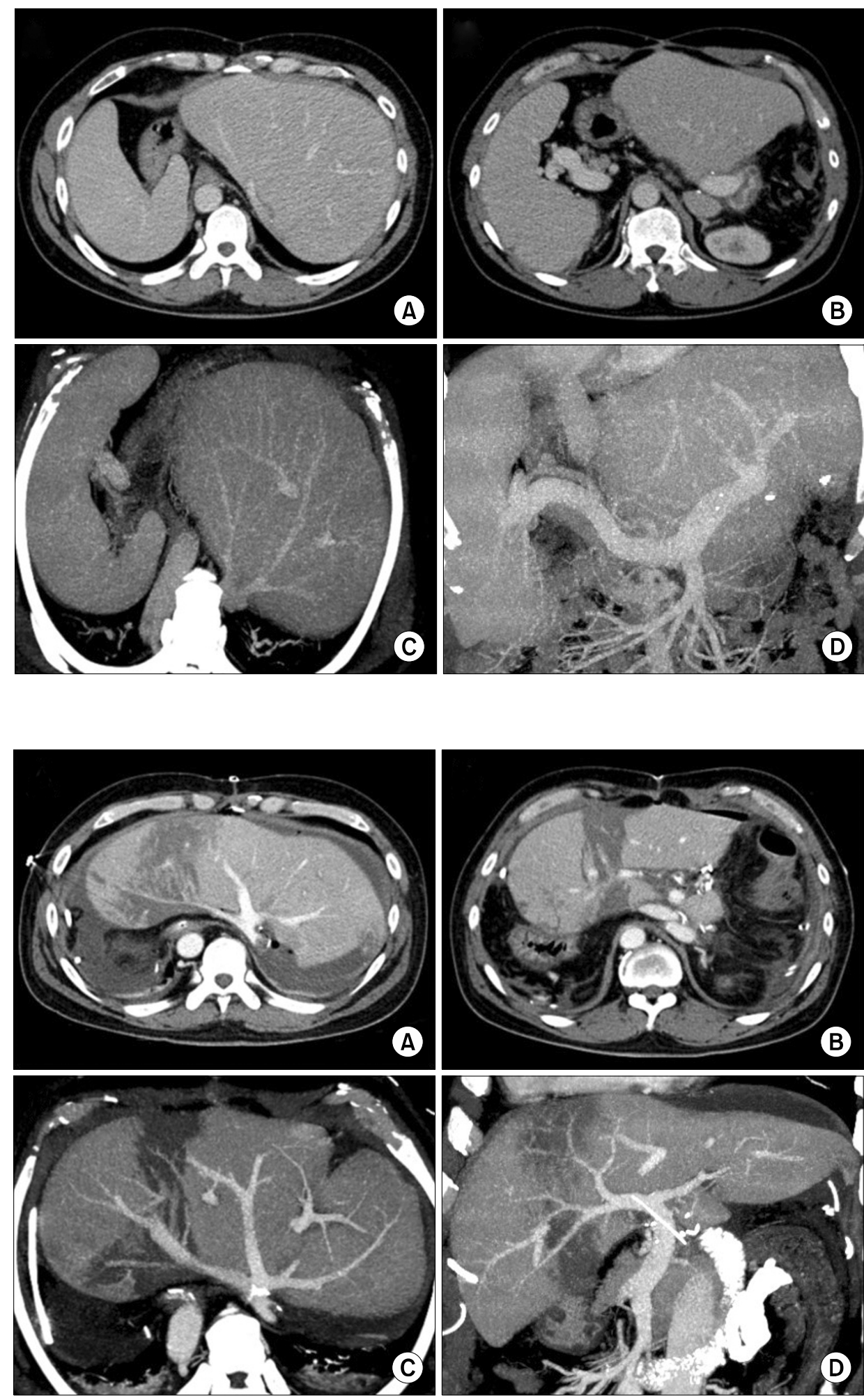

Fig. 5. Posttransplant computed tomography taken 30 months after the first transplantation, showing uneventful hepatic vein (A and C) and portal vein (B and D) anastomoses. The spleen was markedly enlarged.
Fig. 6. Posttransplant computed tomography taken 7 days after retransplantation, showing uneventful reconstruction of the hepatic vein (A and $\mathrm{C}$ ) and portal vein (B and $D)$. The central portion of the liver showed ischemic changes. 

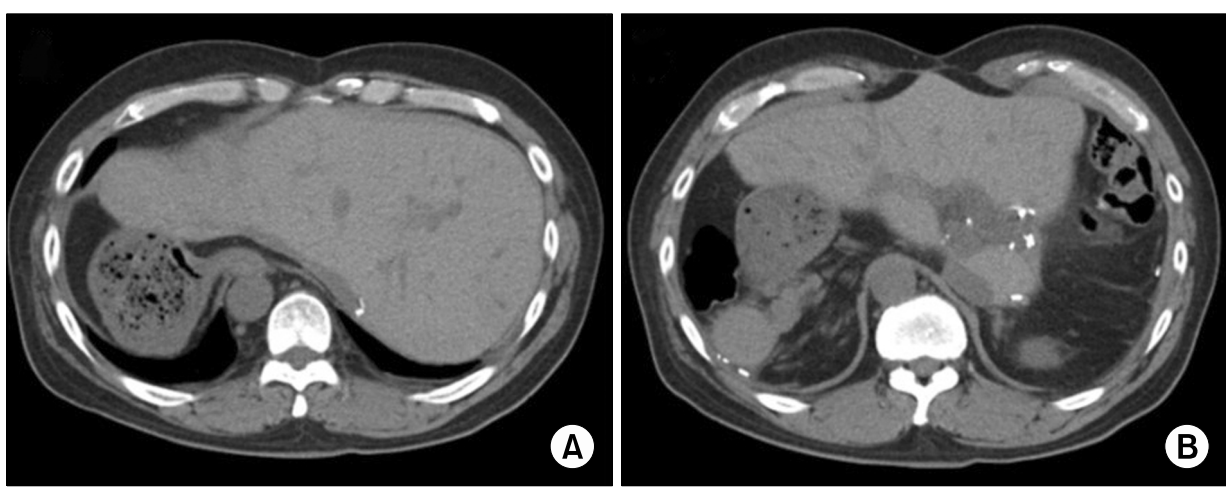

Fig. 7. Posttransplant computed tomography taken 6 years after retransplantation, showing uneventful hepatic vein (A) and portal vein (B) anastomoses.

rated with MELD score of 28 and KONOS old status 2B. After some waiting period, he was finally allocated for whole-liver graft for retransplantation. The donor was a 43-year-old male with height of $174 \mathrm{~cm}$ and body weight of $73 \mathrm{~kg}$. The graft weighed $1760 \mathrm{~g}$, and the recipient's body weight was $83 \mathrm{~kg}$ at that time, thus GRWR was 2.12. After laparotomy, the recipient's first liver graft was removed according to the standard procedures of DDLT. We also performed veno-venous bypass using a centrifugal biopump. When the second whole-liver graft was temporarily placed within the upper abdominal cavity, we found that the right upper abdominal cavity was too small to accommodate the whole-liver graft in the orthodox position. Since the spleen was definitely enlarged, we performed splenectomy to make room to accommodate the bulky right liver of the whole-liver graft. The surgical techniques used for the first DDLT were used again in the second DDLT operation, including large cavocaval anastomosis using a modified piggyback technique, end-to-end portal vein and hepatic artery reconstruction, and duct-to-duct biliary reconstruction. A tissue expander was not necessary in this operation because the left subphrenic space was already shrunken. The recovery of the graft function was delayed because of the extrinsic compression of the liver graft, although there were no surgical complications (Fig. 6). Hospitalization was very prolonged because of very poor general condition and repeated lung problems. This patient was finally discharged 254 days after the second DDLT.

During follow-up at the outpatient clinic, renal function deteriorated progressively, and hemodialysis started at 5 years after the second DDLT. After hemodialysis for 8 months, he underwent living-donor kidney transplantation from his wife. Currently, he is doing well at 10 years after the first DDLT (Fig. 7).

\section{DISCUSSION}

SI is a rare condition characterized by the mirror-image orientation of normal viscera relative to the midline. Its incidence is estimated to be less than $0.02 \%$ of the general population. ${ }^{1-3}$ When the mirror-image rotation abnormalities exist in the abdomen and thorax concurrently, this malrotation is called SI totalis. The etiology of SI is not known to date, but is associated with various congenital abnormalities, including Kartagener's syndrome, polysplenia syndrome, congenital heart disease, and midgut malrotation. $^{18}$

Because of complex anatomic abnormalities, LT for such SI patients was once considered to be contraindicated, but technical advancement led to successful LTs. Previously, the feasibility of LT was reported in pediatric patients. ${ }^{4-17}$ In contrast, adult cases are accumulating worldwide, but there are still only a small number of case reports in the literature. ${ }^{17}$

To perform LT in an adult SI patient, the anatomies of the recipient and donor should be assessed thoroughly before the LT operation. Since the mirror-image location of the abdominal cavity should accommodate the normally-oriented liver graft, donor selection and size matching are the most important steps. If the capacity of the recipient's abdomen is large because of massive ascites, such situation is helpful to overcome the size limit of a whole-liver graft. Smaller grafts permit flexibility in graft implantation and donor-to-recipient weight ratios $<1$ is regarded as optimal for whole-liver transplantation.

So far, various surgical techniques have been described to cope with SI, but no standard approach has been yet 
established. The common procedures reported include orthotopic standard orientation with the donor anatomic right lobe overlying the left side of the recipient's stomach, with combination of large cavaplasty; segmental liver graft from either deceased or living donors; 90-degree clockwise rotation of the donor graft with the anatomic right lobe positioned in the recipient's left upper quadrant; ${ }^{5}$ reversed 180-degree right-to-left flipped graft using reversed cavaplasty; ${ }^{12}$ and auxiliary liver transplantation in a right lateral position in a patient with portal vein thrombosis and other vascular anomalies.

The first DDLT in our present case was done by the most commonly performed procedures, which was orthotopic standard orientation with large cavaplasty using a modified piggyback technique. We paid special attention to making the graft outflow vein orifice as large as possible, because the liver graft would be placed in an unstable position. We reconstructed the portal vein in a standard method. We also inserted a tissue expander to prevent axial torsion or kinking of the outflow and inflow vessels. We gradually removed the water within the tissue expander along the intra-abdominal accommodation of the liver graft. Mechanical support using a tissue expander has been commonly used for dual-graft and pediatric living-donor liver transplantation in our institution.

In this case, facing the second DDLT, the anatomy of the recipient's upper abdomen was changed after the first DDLT. The abdominal cavity was fitted to the first liver graft with disappearance of ascites, and the spleen was enlarged further. Considering that the second liver graft was larger than the first one, the space for the second liver graft must be larger than that for the first liver graft. To make more space at the right-side upper abdomen, the large spleen was resected.

In conclusion, SI is a rare anomalous condition hindering LT. Careful perioperative planning with thorough assessment of the donor and recipient livers and use of patient-tailored surgical techniques can lead to successful LT.

\section{ORCID}

Byeong-Gon Na: https://orcid.org/0000-0002-3150-4645

Shin Hwang: https://orcid.org/0000-0002-9045-2531

Chul-Soo Ahn: https://orcid.org/0000-0002-3844-3646
Deok-Bog Moon: https://orcid.org/0000-0002-8209-3540

Gi-Won Song: https://orcid.org/0000-0002-4235-0434

Dong-Hwan Jung: https://orcid.org/0000-0001-5984-023X

Gil-Chun Park: https://orcid.org/0000-0003-1631-3258

Sung-Gyu Lee: https://orcid.org/0000-0001-9161-3491

\section{REFERENCES}

1. Brassett C, Ellis H. Transposition of the viscera: a review. Clin Anat 1991;4:139-147.

2. Mayo CW, Rice RG. Situs inversus totalis; a statistical review of data on 76 cases with special reference to disease of the biliary tract. Arch Surg 1949;58:724-730.

3. Wood GO, Blalock A. Situs inversus totalis and disease of the biliary tract: survey of the literature and report of a case. Arch Surg 1940;40:885-896.

4. Barone GW, Henry ML, Elkhammas EA, Tesi RJ, Ferguson RM. Orthotopic liver transplantation with abdominal situs inversus and dextrocardia. Am Surg 1992;58:651-653.

5. Klintmalm GB, Bell MS, Husberg BS, Holman MJ, Goldstein RM, Ramsay MA, et al. Liver transplant in complete situs inversus: a case report. Surgery 1993;114:102-106.

6. Watson CJ, Rasmussen A, Jamieson NV, Friend PJ, Johnston PS, Barnes ND, et al. Liver transplantation in patients with situs inversus. Br J Surg 1995;82:242-245.

7. Tang DN, Wei JM, Liu YN, Qiao JC, Zhu MW, He XW. Liver transplantation in an adult patient with situs inversus: a case report and overview of the literature. Transplant Proc 2008;40: 1792-1795.

8. Heimbach JK, Menon KV, Ishitani MB, Nyberg SL, Jankowski $\mathrm{CJ}$, Lindor $\mathrm{KD}$, et al. Living donor liver transplantation using a right lobe graft in an adult with situs inversus. Liver Transpl 2005;11:111-113.

9. Tucker O, Prachalias A, Kane P, Rela M. Graft positioning at liver transplantation in situs inversus. Liver Transpl 2006;12: 1720-1722.

10. Hoyos S, Guzmán C, Correa G, Restrepo JC, Franco H, Cárdenas A. Orthotopic liver transplantation in an adult with situs inversus: an easy way to fit the liver. Ann Hepatol 2006;5:53-55.

11. Wente MN, Thorn M, Radeleff B, Dei-Anane G, Mehrabi A, Sauer $\mathrm{P}$, et al. A routine liver transplantation in a patient with situs inversus: a case report and an overview of the literature. Clin Transplant 2006;20:151-155.

12. Rayhill SC, Scott D, Orloff S, Horn JL, Schwartz J, Zaman A, et al. Orthotopic, but reversed implantation of the liver allograft in situs inversus totalis-a simple new approach to a difficult problem. Am J Transplant 2009;9:1602-1606.

13. Soejima Y, Meguro M, Taketomi A, Ikegami T, Yamashita Y, Harada N, et al. Left lobe living donor liver transplantation in an adult patient with situs inversus: technical considerations. Transpl Int 2008;21:384-389.

14. Kim BW, Bae BK, Xu W, Wang HJ, Kim MW. Living donor liver transplantation for an adult patient with situs inversus totalis. World J Gastroenterol 2010;16:2311-2313.

15. Yu S, Guo H, Zhang W, Yu J, Yan S, Wu J, et al. Orthotopic liver transplantation in situs inversus adult from an ABO-incompatible donor with situs inversus. BMC Gastroenterol 2014;14:46.

16. Kamei H, Onishi Y, Ogawa K, Uemoto S, Ogura Y. Living donor liver transplantation using a right liver graft with additional 
vein reconstructions for patient with situs inversus. Am J Transplant 2014;14:1453-1458.

17. Tabrizian P, Joseph TT, Radkani P, Cohen E, Facciuto M. Liver transplantation in an adult recipient with situs inversus totalis: case report and review of the literature. Transplant Proc
2016;48:3163-3166.

18. Niikawa N, Kohsaka S, Mizumoto M, Hamada I, Kajii T. Familial clustering of situs inversus totalis, and asplenia and polysplenia syndromes. Am J Med Genet 1983;16:43-47. 